\title{
A política cultural no acordo Mercosul
}

\section{HUGO ACHUGAR}

imón Rodríguez propôs, no início do século XIX, a contraditória opção: "Ou inventamos ou erramos". Talvez hoje pudéssemos parafrasear as palavras do professor de Simón Bolivar afirmando: "integramos ou erramos". Na verdade, deveríamos dizer "inventamos, integramos ou erramos". Sem dúvida, antes de continuar, é necessário esclarecer o tema desse discurso, isto é, quem é o nós nesta oportunidade. A dramaticidade presente na fórmula inventamos, integramos ou erramos só parece válida para os uruguaios, e, talvez em menor escala, para os paraguaios, embora eu não deseje assumir uma voz que não me pertence. A integração não é - ou não parece ser - uma opção fundamental para argentinos e brasileiros. Por isso, o nós deste discurso só se torna dramático para os uruguaios; inclusive é possível que a estratégia operante que joga tudo na integração represente apenas alguns setores da sociedade uruguaia.

Mas a integração - com ou sem dramas - dos países do Mercosul supóe uma alta quota de invenção. Não me refiro apenas à invenção política, conceitual, econômica, mas também à cultural. Sem dúvida, este mundo globalizado coloca dificuldades ao mesmo tempo em que favorece os regionalismos. Desses aspectos, e dos desafios às identidades locais e regionais, tratam as reflexóes que seguem.

\section{O espaço da cultura no Tratado do Mercosul}

A integração regional do Mercosul, além dos prazos previstos no Acordo Marco em chegar à tarifa zero em 1995, e sobretudo além de tais prazos serem reformulados ou postergados, é uma realidade que já começou a afetar tanto a realidade jurídica como a econômica, a educacional e a cultural. Na verdade, mais que uma realidade, o Mercosul é " uma geografia à espera de atores", como afirmou Jorge Schvarzer (1). $O$ economista argentino assinalou as dificuldades do tempo, mas também as vantagens do espaço (espaço restrito, espaço unificado, transporte e comunicaçōes) e das fronteiras vivas, assim como o tema da infra-estrutura de comunicaçôes na regiāo, como condiçôes para o processo de integração regional. Processo que hoje - diferentemente dos 
anos 60 - pode ser viável a médio prazo, embora os atores sociais ainda náo estejam dispostos a trabalhar.

Mas essa eventual conjunção de tempo e espaço não cobriria a totalidade dos países envolvidos. A esse respeito, não só Schvarzer, mas também Germán Rama ressaltaram que o processo de integração abrangeria o eixo constituído por Buenos Aires e Rio de Janeiro. Nesse sentido, Rama observou que a integraçáo se projeta sobre uma zona que abrange Rio de Janeiro, Sáo Paulo, Montevidéu e Buenos Aires, e que concentra três-quartos da produção industrial da América do Sul. Esses dados não são notórios, a não ser na hora de considerar o alcance e os efeitos sobre a esfera cultural da regiáo.

O caráter econômico da integração explica o fato de que não haja referências à cultura e a políticas culturais no Acordo Marco de Assunção. Além disso, nas discussóes da Câmara de Representantes (Deputados) do Uruguai, as referências à cultura - quando existem - são retóricas e apresentam-se vinculadas a problemas de identidade nacional.

Assim, o deputado Machiñena, relator geral da Comissão, que estudou o Acordo Marco e apoiava a ratificação, referiu-se a aspectos culturais apenas para indicar a posição privilegiada do Uruguai, em que, o "nível cultural de nosso povo" e sua "preparaçáo torna o país mais atraente para os investimentos" (2).

Por outro lado, o relator da minoria, Deputado Helios Sarthou, que se opunha, afirmou: "Temos muito receio da articulação do Tratado de Assunçáo com o chamado Tratado Quatro mais Um, além dos compromissos temporais, pela profundidade das medidas que podem nos relegar às margens da zona integrada, no papel de provedor de serviços em uma divisão de trabalho conveniente para as multinacionais ... com nossa identidade nacional comprometida" (3). Em outra passagem, o mesmo deputado assinala: "As carências sobre temática social se reiteram também no que diz respeito aos aspectos culturais, de grande transcendência na hipótese de integração" (4).

O que foi estabelecido no Tratado e realizado pelas autoridades com relação à cultura, durante esse período chamado de transiçáo, reduziu-se a três aspectos: declaraçóes sem efeito jurídico sobre cultura, sendo esta entendida em sentido tradicional; uma ou duas reuniōes referentes a aspectos educacionais e a possibilidade de compatibilizar currículos e estabelecer sistemas de revalidaçōes - embora valha a pena destacar que as universidades foram as que mais avançaram nesse aspecto, como demonstra a presente reuniáo de Porto Alegre; e problemas 
vinculados à propriedade intelectual. Justamente o terceiro aspecto é o que tem implicaçóes econômicas evidentes, e tem sido impulsionado por alguns setores da indústria cultural; concretamente, a indústria discográfica, que se mostrou preocupada com a pirataria realizada por alguns setores da indústria paraguaia. Com relação a esse aspecto, formou-se uma subcomissão da equipe econômica, que trabalha no período de transição do Acordo Marco e é composta de representantes dos setores industriais e assessores técnicos do Ministério da Economia.

Essa espécie de subtexto econômico ou de trama básica do Mercosul relegou os temas culturais e acadêmicos para o espaço da retórica, e não conseguiu avançar em suas projeçóes. Em outras palavras, os Estados participantes do Acordo Marco de Assunçáo limitaram-se ao que o Tratado estabelece: um mercado comum em níveis industrial e comercial tradicional, sem incorporar a indústria cultural ou sem pensar que o peso econômico dessa indústria seja relevante. Ignorando, ou melhor, depreciando desse modo a possibilidade de permitir um espaço de integração cultural. Sem dúvida, antes de continuar, acho necessário narrar uma pequena história, como digressão.

\section{Uma pequena história}

Nem bem se começa a falar de integraçáo, e em especial de políticas culturais, vários personagens aparecem. Naçáo, Identidade, Tradição, Modernização e Mercado surgem quase que imediatamente, porém também surgem outros, talvez mais abstratos: a Homogeneidade e a Heterogeneidade.

A Homogeneidade e a Heterogeneidade sáo personagens recorrentes nos cenários da reflexáo cultural do presente e do passado. Nos tempos da organização e construção dos Estados nacionais latino-americanos, no final do século XIX, a vontade política nacionalista ofereceu/impulsionou um modelo homogêneo de educaçáo e cultura. A civilizaçáo - racional, iluminista e com fé absoluta nos progressos moral e material dos povos - deveria cobrir homogeneamente os territórios nacionais. A diferença cultural dos subalternos devia ser subjugada ou, mais ainda, confinada ao espaço do folclore. Os intervalos militares, em alguns países, enrijeceram a vontade homogeneizadora com maior repressáo. Por sua vez, em outros países, como o México, essa vontade homogeneizadora teve perfis mais democráticos ou, pelo menos, reconheceu a heterogeneidade básica da nação.

Mas a Heterogeneidade, personagem tenaz e obcecada, terminou 
por demonstrar que o acionar dramático da Homogeneidade era ilusório. Nos últimos tempos, alguns acadêmicos ofereceram legitimidade aos protestos da Heterogeneidade. Sem dúvida, esta não tinha ficado paralisada durante os embates da Homogeneidade, pois os chamados movimentos de resistência e também a cultura de resistência dos grupos subalternos entorpeceram o trabalho da Homogeneidade.

No momento presente, os estudiosos do drama alegórico Homogeneidade versus Heterogeneidade já puderam constatar e estimular a ação dos dois personagens. Mas não são apenas eles que intervêm: os cientistas sociais, os pensadores da intelligentzia - urbana e democrática - $\mathrm{e}$ os administradores políticos também tiveram seu papel.

Papel particularmente evidente quando se legisla sobre ou quando se estudam as políticas culturais. Papel que se torna complexo, especialmente para aqueles que desejam ou aspiram a um cenário democrático e náo ao apocalipse. Pois, como conciliar o impulso inconsciente para a homogeneizaçáo - próprio de toda legislaçáo ou de toda política cultural e evidente no mero fato de ser plano e programa de administração e promoção - com a preservaçáo democrática de uma realidade múltipla e heterogênea? Nesse sentido, como sustenta Leandro Konder, hoje o liberalismo e o socialismo aspiram a propostas de políticas culturais democráticas e pluralistas (5).

Como fazê-lo, quando do nacional se passa ao regional multinacional! Como fazê-lo, quando foram subindo ao palco os outros personagens: Nação, Identidade, Tradição, Mercado, Regiáo, América Latina, Pátria, Cidade natal etc?

A Naçáo, a Identidade e a Tradição aparecem como aliadas da Heterogeneidade. Sem dúvida, o Mercado tem tido um comportamento inconstante. $\mathrm{E}$ agora seu funcionamento se vê comprometido pelos processos de integraçáo. A lógica interna tradicional do personagem supunha sua aspiraçáo à totalidade. O Mercado aspirava a crescer sem demora nem medida, e seu horizonte virtual era a totalidade do planeta. Fenômenos que se chamam ou chamaram colonização, globalização e transnacionalização fugiam da alçada do Mercado. A revoluçăo tecnológica e o conflito do Mercado com a Indústria, a Empresa e o Estado criaram outro personagem derivado: os Nichos de Mercado. Mas os Nichos de Mercado são produtos da estratégia tanto dos países poderosos como dos fracos.

O drama alegórico e a pequena história são narrados de modo diferente pela comunidade acadêmica e pelos homens e mulheres que 
produzem tanto mercadorias como símbolos. No estudo das políticas culturais no processo de integraçăo regional, que compete a nós, as personagens Homogenèidade e Heterogeneidade são antagônicas, e esse antagonismo está presente na mera formulaçăo de uma política cultural. Todo estudo de políticas culturais, assim como toda elaboraçáo de políticas culturais futuras, deve ter consciência do referido antagonismo. Dele, e da tensão que a Nação e a Transnacionalização estabeleceram neste final de século.

\section{Sobre identidades, espelhismos e novos cadinhos}

A escrita é, como já sabemos, um ato de violência. A escrita do letrado que pretende descrever o rosto da nossa América tem sido um exercício reiterado dessa violência. A possibilidade de que toda intençáo de dizer o que é o outro ou o que somos nós esteja marcada pela violência da apropriação e da redução torna a reflexáo sobre a identidade um discurso suspeito. Apesar disso, esse discurso suspeito e violento náo pode ser refreado quando se consideram os processos culturais e sociais de nossos países; mais ainda, caso se pense nos processos de integraçáo.

O tema da identidade tem sido esgotado pela Academia e, de certo modo, é um âmbito de reflexáo particularmente desvalorizado; pelo menos o esteve, durante as últimas décadas. Sem dúvida, os múltiplos processos de identidade têm sido objeto de estudo e de reflexáo a partir de novas perspectivas ou de novos ângulos, especialmente com relaçáo à identidade cultural. Nesse sentido, quando Nestor García Canclini fala de culturas bibridas, ou quando Fernando Ortiz e depois Angel Rama falaram de processos de transculturafaio, a elaboraçáo conceitual sobre os processos de identidade cultural em nossos países articulou-se de outra maneira. Por outro lado, fala-se hoje também em novos fundamentalismos religiosos e nacionais. Acho que, além das especificidades dos problemas referidos em tais noçóes ou dos mencionados fundamentalismos, estamos diante de um processo particular na constituiçáo das identidades individuais, grupais, nacionais ou regionais.

A Identidade é uma personagem que aparece acompanhada de um par de atributos. Por um lado, segura um espelho e por outro carrega um cadinho, uma retorta. Em alguns cenários há variantes: a Identidade não é um personagem único, e todos estáo acompanhados de espelhos. Em outros, a Identidade é uma espécie de indivíduo mal passado, detido e congelado em plena metamorfose; neste último cenário, o cadinho náo se refere a um passado mas a um processo em andamento. Em algumas versóes a Identidade disse: "Tupi or not tupi, eis a questão", em outras Próspero pinta os nomes do personagem como em uma tela medieval e 
os chama de "Caliban", "Ariel", "Esmeralda", "Sexta-Feira", "Foe".

Sem dúvida, o tema não passa por essa multiplicidade de cenários e personagens. Pelo menos não o que me interessa ou nos interessa nestes dias. O que importa - certamente influenciado por minha condiçáo de uruguaio - é que o processo de integração atualiza o problema (utilizo a expressão problema deliberadamente) da identidade regional. Náo somos apenas uruguaios, argentinos, paraguaios, brasileiros, cone-sulinos (tenho dúvidas de que todos os brasileiros se reconheçam no rótulo de Cone Sul) mas, além da nossa condiçáo de latino-americanos, agora teríamos essa outra, de Merco-sulinos.

E eu me pergunto: em que medida essa identidade regional existe ou é prơposta pelo processo de integração? Em que medida nos reconhecemos ou podemos ser interpelados por essa identidade regional?

Em que medida todo esse processo de integração não faz entrarem em crise identidades pré-existentes, mais do que provocar novas identidades? Em que medida não se está promovendo uma identidade que abrange geograficamente o eixo Buenos Aires-Montevidéu-Porto Alegre-Curitiba, deixando de fora Bahia, Manaus, Salta, Jujuy etc.?

A realidade econômica que sustenta o Mercosul apóia-se, como vimos, na área industrial que vai de Buenos Aires a São Paulo e Rio de Janeiro, e ignora as margens. Nesse sentido, a integraçáo estaria empreendendo uma nova distribuição internacional do trabalho dentro do Mercosul. Em que medida os prósperos do eixo Buenos Aires-São Paulo não estáo escrevendo, empunhando um espelho, pintando pequenos cartazes que identifiquem os habitantes da zona! Em que medida a integraçáo econômica năo supóe uma violência identificatória igual ou maior que a violência identificatória que vem proposta pelos logotipos do McDonald's e da Benetton?

Para a sociedade uruguaia, além desses temores, há outros. Nesse âmbito, nesse cenário nacional, o dilema parece situar-se entre a angústia da viabilidade econômica e a viabilidade da identidade. Os prósperos vizinhos náo nos deixaram alternativa, e acompanhamos o drama.

A eventualidade de um cadinho regional multinacional que antecipe a uniāo e a fusáo latino-americana não parece ser mais que uma figura de retórica. A mestiçagem, a transculturação ou a hibridez - três fenômenos distintos - operam e operaram nas distintas regiōes da América Latina. Sem dúvida, propor ou supor que o processo de integraçáo do Mercosul estimule esse grande cadinho da Pátria implica desconhecer o fundamento econômico do Acordo Marco de Assunçáo, e, 
sobretudo, implica desconhecer a localização fundamental desse eventual Mercado Comum do Cone Sul no eixo Buenos Aires-São Paulo. Implica, além disso, outro problema vinculado ao processo de construçáo de imaginários, que veremos mais adiante.

É possível que, apesar de tudo, o processo favoreça a integraçáo econômica e talvez a cultural de um centro regional e que esse centro administre suas próprias periferias. Assunçáo e Montevidéu estão lutando para não serem meras periferias, mas o nordeste brasileiro, o norte e o sul da Patagônia na Argentina certamente não deixarão de ser periféricos.

Centro ou periferia econômica; identidade marginal ou central, o Mercosul coloca, ou melhor, esboça um novo mapa de identidade em mais de um sentido, em mais de um nível.

\section{Mundo, região e comarca}

O processo de integraçáo regional acompanha o fenômeno de globalização que, por sua vez, presencia o fenômeno do isolamento típico de uma aldeia da comarca. Os fenômenos de integraçáo que estamos vivendo pressupóem, além dos aspectos econômicos, os culturais. Entendendo por cultural não só os educacionais ou os artísticos, como todos aqueles que, de algum modo, possam ser incluídos na produção simbólica sem nos reduzir ao beletrismo.

A particularização lingüística e cultural que voltou a despontar em nossos dias está sob a tensáo da presença marcante dos meios audiovisuais, que tendem à homogeneizaçáo. Ou, em um sentido mais brando, que tendem à construçáo de um imaginário multinacional. A possibilidade de construir imaginários multinacionais regionais pressupóe problemas de língua, mas, sobretudo, de indústria cultural, de políticas educacionais. Em nossos países, a recepçáo diferente e desigual dos produtos simbólicos elaborados em nível nacional ou local na regiáo mostra como estamos longe de que os meios de comunicaçáo - particularmente os audiovisuais - estejam trabalhando na configuração de um imaginário multinacional da região. $\mathrm{Na}$ realidade, isso nunca esteve na agenda das indústrias culturais, nem na dos Estados dos países do Mercosul.

A barreira lingüistica é mais um pretexto que um verdadeiro obstáculo. Há exemplos em outras regiōes do mundo, nas quais coexistem comunidades multilingüísticas com uma intensa integraçáo imaginária ou nacional. Também é evidente que as diferenças de língua deram e dáo margem para nacionalismos e bairrismos exaltados. Sem dúvida, em 
nossos países, o tema lingüístico não pode constituir, desde já, um argumento contra a integração; a Comunidade Européia é uma comunidade multilíngüe e isso não impediu seu processo de integração.

Além disso, o tão propalado imaginário produzido pela globalizaçáo, a que a transformaçáo gerada pelo alcance dos meios televisivos nos está conduzindo, é um imaginário traduzido. Nesse sentido, talvez se pudesse afirmar que integração supóe tradução. $O$ que nos leva, na verdade, à integração que não passa exclusivamente pela homogeneizaçáo, nem pela construçáo de universos imaginários pasteurizados.

O universo cultural em sociedades de homogeneidade frágil ou de relativa heterogeneidade - como săo, em diferente medida, as sociedades dos quatro países do Mercosul -, com fragmentação crescente e cercadas (ou beneficiadas?) pela iminência de uma integração regional, tem diante de si muitos problemas para resolver. Quando se abandona a descrição do passado e do presente para começar a realizar projetos, utopias ou simplesmente politicas culturais a serem desenvolvidas em um futuro a curto, médio ou longo prazo, torna-se primordial a consideração dos agentes dessas políticas.

Colocando o tema de modo mais brutal, seria possível perguntar: quem sáo os responsáveis por esse futuro? O Estado, os empresários, os diversos criadores, os próprios consumidores (quase nada ou nada organizados)? E também: qual é o papel dos acadêmicos nessa tarefa? De acordo com o proposto não com relação às políticas culturais regionais, mas nacionais, por um certo número de funcionários e criadores, parece que o Estado tem ou deveria ter uma responsabilidade maior. Outros têm proposto que a participação dos empresários deva ser crescente. É claro que o tema foge a estas consideraçóes e se liga ao atual debate sobre o papel e a dimensão do Estado, assim como ao diálogo entre os diferentes atores.

No que se refere ao Uruguai, as transformaçóes culturais no âmbito da integração regional, e levando-se em conta as características de um país pequeno em nível geográfico e demográfico, colocam graves problemas para uma identidade nacional e cultural frágil. O país é pequeno também em termos econômicos, e isso, por sua vez, cria problemas para o desenvolvimento e o estímulo da atividade cultural frente ao poder econômico - não só de nossos vizinhos imediatos - mas das grandes indústrias culturais multinacionais. Mas é possível falar de um país pequeno em termos culturais? Qual ou quais seriam as estratégias para preservar, potencializar e criar a cultura ou as culturas de um país? Perguntas semelhantes poderiam colocar-se para a regiăo, caso se leve 
em conta o poder dos países chamados de Primeiro Mundo e o poder econômico das indústrias culturais multinacionais.

O peso das diferentes culturas (ou subculturas), a dinâmica do diálogo entre os diferentes atores envolvidos no fenômeno cultural $e$, sobretudo, o investimento estatal ou privado seráo parte fundamental do futuro, particularmente no âmbito da integração regional. A alternativa proposta por alguns setores de cada um dos nossos países de integrar-se ao mundo e não à região, ainda que defendida com firmeza a partir de certos centros de poder econômico e político, náo parece ter igual força na Argentina como no Brasil, no Uruguai como no Paraguai. A alternativa de uma integração ao mundo reforçaria aspectos de uma tendência tradicional em nossos países para a consolidação de uma cultura de importafão, já presente hoje em dia e favorecida pela difusão do imaginário globalizado a que fiz referência.

\section{Capital cultural herdado, valor e integração}

Para terminar, acho importante considerar a existência de um nível geral, conceitual e até certo ponto filosófico (embora não no sentido mais literal do termo filosofia) que vem à tona na discussáo da manutençăo tanto das políticas culturais como das noçóes de identidade, integração regional, modernidade, contemporaneidade, utopia, passado e futuro.

$\mathrm{Na}$ discussáo atual sobre esses temas, creio perceber náo só a persistência de antigas posiçóes (pelo menos no âmbito cultural metropolitano e periférico constituído pelo que se chama Ocidente ou 0 outro Ocidente), como também, e principalmente, a dificuldade na avaliação do que são as distintas beranças culturais recebidas. Heranças nem sempre seculares, algumas muito recentes. Depois de todo o pacote da ou das "heranças culturais" ou dos "capitais culturais" (Bourdieu), temos tanto o Iluminismo, a modernidade hegemônica, como a modernidade crítica, a reprodução mecânica das obras de arte, as práticas culturais populares e as práticas culturais folclóricas, a televisão e o computador. Mais ainda, a heranfa cultural inclui, pelo menos para os latino-americanos, tanto o cinema do telefone branco, dos anos quarenta e cinqüenta, como o cinema de María Luisa Bemberg; tanto a arte warao como os happenings da Minujin, a ação do chileno Zurita como o artesanato de Manos do Uruguai. Tais heranças incluem - e năo só para os latino-americanos - tanto o anáo de jardim como os anjinhos neobarrocos, o cinema de Ingmar Bergman e os programas de Olmedo, as instalaçōes de Julio Le Parc com aqueles versos inesquecíveis que dizem "Esta noite vi chover, vi gente correr, e tu náo estavas". Como avaliar 
todos esses valores? A pergunta não é superficial. Realmente, o juízo de valor, ou melhor, os juízos de valor explícitos e implícitos em muitas das presentes reflexóes apontam para o centro das questóes debatidas aqui. Como elaborar políticas culturais nacionais ou multinacionais, integradoras ou bairristas, sem resolver a questáo de valor com relaçáo a nossas múltiplas heranças culturais? Como reconhecer aqueles elementos constituintes de nossas identidades e sobretudo das identidades dos outros, sem avaliar? Mais ainda, como integrar multinacionalmente sem avaliar a partir de onde integrar?

Alguém pode propor a integraçáo a partir dos meios audiovisuais, mas de quais? Dos meios audiovisuais que temos ou de como desejaríamos tê-los? A integração por bolero, bossa nova, telenovela brasileira, cinema de Solanas, cinema de Glauber Rocha, cinema do telefone branco supóe distintas avaliações do passado, do presente e principalmente do futuro.

O debate passa então pela existência de um centro nevrálgico, que é a avaliação das múltiplas heranças dos capitais culturais que recebemos. Nesse sentido, noçóes como homogeneidade e heterogeneidade, delegação da soberania, elaboração de confronto, mal-estar na cultura, democracia, pós-nacionalismo, globalização, língua, tradução, regressão ou perda cultural estáo atravessadas por tentativas de descrever situaçóes presentes e passadas, porém de um modo mais decisivo, por tentativas de dividir as águas, de desenhar um mapa de paraísos e infernos.

Reconhecer que nảo podemos escapar à avaliaçăo é um fato possivelmente sem importância. Reconhecer que as avaliaçóes, e não só as heranças culturais, são múltiplas, acho que está marcando a nossa época. O problema começa quando, além de reconhecer a multiplicidade e a heterogeneidade cultural de um período de inflexão pós-nacional, passamos a exigir democracia ou, para utilizar uma imagem de Richard Rorty, a conversa. Se fosse válido pensar que durante a modernidade o que tivemos foram monólogos (expressamente fundamentalistas ou não) impostos de cima, pareceria que a tarefa do presente consiste em facilitar os âmbitos da conversa.

Nesse sentido, pareceria que o trabalho e não só a filosofia das políticas culturais de integraçáo em nível multinacional, mas também nacional ou urbana, seria elaborar espaços de conversa onde a avaliação múltipla pudesse delegar parte das soberanias com a finalidade de poder construir espaços realmente democráticos. Parece-me que a alusáo de Herman Glasser (6) aos problemas da linguagem e principalmente aos problemas de traduçáo permite pensar em tais espaços de conversa como 
espaços de tradução. Sabemos que toda tradução pressupóe uma traiçáo; o que talvez devêssemos aprender é que a perda/traiçáo gerada pela traduçáo náo implica, necessariamente, o negativo. $O$ poder destrói, reprime, mas também permite e constrói.

O problema, um dos muitos problemas que tudo isso coloca, relaciona-se intimamente com o de identidade ou identidades. A passagem do singular para o plural náo é casual. Justamente o desafio, em nível do indivíduo, do grupo ou classe, da cidade, da naçáo e da regiáo que apresenta o problema da identidade relaciona-se aos problemas do discurso. Quando, hoje em dia, tanto o indivíduo como o sujeito coletivo têm dificuldade para dizer eu como para dizer nós, quando as mulheres dizem nós, colocam-se o problema (Teresa de Lauretis, entre outras) de se esse nós não é uma categoria homogeneizadora que anula especificidades fundamentais e que, portanto, se torna uma categoria ideologizante. Dizer nós, os latino-americanos, ou nós, os uruguaios, năo está afetado pelo mesmo problema?

Não foi só o muro de Berlim que caiu, caíram também as seguranças discursivas da identidade coletiva. Sem dúvida, o desafio é que, reconhecendo a diferença e a multiplicidade, reconhecendo e tolerando o diferente, possamos construir uma identidade coletiva. Porém, para construir democraticamente uma identidade coletiva, necessitamos, num jogo de palavras, de políticas culturais democráticas. Políticas culturais democráticas e não falsamente democráticas. Isto é, políticas culturais que reconheçam diferenças quantitativas e qualitativas, mas que náo se imponham monologicamente.

Năo se trata de criar espaços de conversa nos quais a delegaçáo de soberanias implique a construção do somos todos iguais. Criar espaços culturais democráticos também náo supóe delegar a identidade ou a soberania às leis do mercado selvagem. O mercado é uma realidade $\mathrm{e}$ uma constante no debate da integraçáo - náo somente pelo fato de que as integraçōes regionais do TLC e do Mercosul sejam fundamentalmente comerciais; a discussáo colocada passa náo pela realidade do mercado, mas pelo endeusamento ou pela esconjuraçáo do mercado.

Ao mercado selvagem se opõe a noção de democracia solidária. Permitir um mercado democraticamente solidário é um desafio para a elaboraçáo de políticas culturais. Os centros culturais - de experiência desigual e de destino muito diverso nos diferentes países do Mercosul - poderiam ser, deveriam poder ter sido espaços de conversa, e de construçáo de identidades culturais democráticas (7).

É possível que a solução dos centros culturais na América Latina 
não tenha funcionado de forma igualmente positiva. É possível que essa solução cultural seja hoje questionável, ou necessite de uma reformulação tecnológica. O resgatável, me parece, é a necessidade de possibilitar espaços de construção de identidades coletivas democráticas.

A informatizaçáo, a internacionalização e a globalizaçáo da cultura pareceriam ter tornado obsoletas certas formas de produção e de organização válidas no passado. Sem dúvida, náo acredito que o novo espaço cultural - não me refiro ao espaço físico, mas ao simbólico - passe pela construção de um laboratório equipado de computadores, cabines de simulaçáo de vôo, vídeos e antenas parabólicas.

O espaço cultural de um futuro integrador e integrado que náo seja apocalíptico, passa pela conversa. Uma conversa que implica, além disso, a elaboraçáo dos múltiplos confrontos que os diferentes sujeitos e inumeráveis indivíduos devem processar. Quer dizer que devemos pôr para conversar o torturador com o torturado, a mulher espancada com o homem violento, o jovem desprezado com o geriátrico autoritário, o índio camponês com o gerente branco, o político corrupto com o aposentado empobrecido ou estressado? Implica isso a convivência do estuprador com a vítima? A realidade atual de muitos de nossos países faz com que convivam estuprador e vítima, sem que tenha ocorrido o confronto. A convivência atual é a convivência da impunidade. A convivência futura deve passar pela elaboraçáo do confronto que impeça a reiteração do passado. Construir uma identidade coletiva e regional, inclusive de mercado regional, passa por poder não repetir o passado. E, para não repetir um passado que um setor de nossas sociedades acha válido. Porque é assim, muitos de nossos concidadãos - palavra horrível acham válido o passado de violaçáo e de violência. Parece-me que devemos construir espaços culturais que permitam aperfeiçoar o passado.

Isso pressupóe políticas culturais claras, que náo estejam submetidas às leis do mercado. Políticas culturais que náo sejam apenas políticas comerciais para o manejo dos bens culturais. $O$ que não quer dizer que não devam existir políticas comerciais e industriais de Estado e não de grupos ou de governo com relaçáo à cultura.

Para terminar, gostaria de considerar outro aspecto vinculado à avaliaçăo. Mais exatamente ao valor de mercado e não às avaliaçóes política, ética ou filosófica. A revoluçáo cultural a que George Yúdice aludiu pressupóe a internacionalização do mercado mas também a fixação dos valores do mercado cultural (8). E essa é uma dimensáo que está presente no debate, mas não necessariamente nas investigaçóes acadêmicas sobre identidade e sobre cultura. A dimensão de base da cultura não 
parece ser considerada digna da reflexáo. Paradoxalmente, a importância econômica, assim como o impacto em nível da força de trabalho das chamadas indústrias e serviços culturais, são crescentes. Eu diria mais ainda, numa sociedade na qual a revolução tecnológica e a revolução dos meios de comunicação geraram o impacto que todos nós conhecemos mesmo no caso de sociedades periféricas como as nossas - o tamanho econômico e a projeção na força de trabalho da indústria cultural são de um peso surpreendente. Isso não foi aprendido ainda pelos economistas, como não o entenderam os políticos e sobretudo custa a muitos de nossos colegas acadêmicos que vêem na cultura um setor improdutivo, um conjunto de produtos com alto valor de uso e reduzido valor de troca. A antiga desvalorização real do tema cultural, por parte de políticos e de autoridades acadêmicas, dificultou a formação de agentes capazes de propor políticas culturais que não sejam retóricas, incidam no mercado, e não o sigam com atraso em seus avatares.

O mercado de artes plásticas não é o único âmbito no qual está presente e assume valor, é claro que isso não necessita de maior desenvolvimento. Talvez uma das heranças mais persistentes da modernidade, e com uma aura indiscutível, para voltar ao começo, seja a da autonomização da esfera cultural. Essa autonomização da sociedade civil, mas também o intuito de autonomizar a arte e a cultura das leis do mercado, contribuiu para criar ou reforçar a noção de que arte e cultura não eram zonas produtivas. Mais ainda, entendeu-se que cultura e mercado eram inimigos, que sua relação implicava a degradação da cultura. Isso levou ao financiamento problemático e deslocou muitas vezes a discussáo para temas vinculados a financiamento público ou privado da cultura.

O espaço democrático a ser construído por políticas culturais integradoras em todos os níveis náo pode desconhecer o tema do valor econômico. É impossível desenvolver espaços culturais democráticos, multiculturais, nos quais se integre a partir da tolerância e não se imponha o confronto sem que haja elaboração, processamento, e que o esquecimento não suponha impunidade, digo que é impossível o referido desenvolvimento sem atender aos problemas concretos do valor econômico da cultura. Uma política cultural democrática não é possível sem um desenvolvimento econômico e, sobretudo, sem um investimento considerável. Os centros culturais, os laboratórios de informática, os simuladores tecnológicos onde os pilotos do presente e do futuro cheguem à conversa democrática não são possíveis, é óbvio, sem investimento.

Atender aos aspectos econômicos tanto das indústrias culturais como da ação do Estado é atender também à constituição de identidades 
que já não se constroem tanto no espaço nacional, mas, como ressaltou García Canclini, em um espaço transnacional e pós-nacional. Certamente isso exigiria o aprofundamento da discussão sobre a validade ou não da categoria de nação no debate sobre a identidade $e$ as políticas culturais. Se a Pepsi-Cola ou a Coca-Cola são ou foram elementos fundamentais na construçăo de identidades em muitas regióes do Ocidente, não me parece que seja um debate banal e que certamente não possa ser colocado em termos de imperialismo cultural. A identidade do guerrilheiro salvadorenho que, com boina à Che Guevara, camiseta com o logotipo da Coca-Cola e metralhadora na mão, declara sua adesão à Frente Farabundo Martí em uma entrevista pela televisão, alguns anos atrás, é a imagem de uma identidade construída pelas multinacionais, pelo discurso do colarinho branco dos anos sessenta, e é uma comprovaçáo de que os processos de identidade náo podem ser simplificados nem esconjurados a partir de uma louvaçáo estreita dos valores do passado. É evidente que náo devemos, tampouco, jogar fora o bebê com a água da bacia da herança cultural hegemônica e contracultural.

\section{Final}

A problemática integração econômica dos países do Mercosul irá se realizar, ou não, em um prazo mais ou menos imediato. A hipotética e utópica construção de uma identidade e de um imaginário regional multinacional não é decretável, embora pudesse ser estimulada. Os desafios civilizadores do presente e a tensão entre a globalizaçáo e o bairrismo deverão modelar as identidades culturais de cada um de nossos países, assim como da região. Podemos nos resignar àquilo que o mercado construa, ou podemos orientá-lo utopicamente para a realização de um imaginário regional. As opçóes estão aí. Os atores sociais terão de decidir e nós, os acadêmicos, poderemos decidir acompanhar os processos, interpretando-os ex post facto, ou promover mudanças. Entre a resignação e as opçóes, há lugar para a invençáo. Repetir sem elaborar é uma forma da inércia. Para não repetir os erros do passado, ainda com a exígua experiência de integraçáo cultural de nossos países, só nos resta a invençăo. Uma vez mais, com Simón Rodríguez, "Ou inventamos ou erramos".

\section{Notas}

1 Jorge Schvarzer. El Mercosur, la geografía a la espera de actores. In: Nueva sociedad, n.126, jul./ago. 1993. 
2 Diario de sesiones de la Camara de Representantes, n.2.200, t.659, p.112 e ss.

3 Idem, ibidem, p.104.

4 Idem, ibidem, p.108.

5 Leandro Konder defende em Teses sobre política cultural, in: 1994, ideias para uma alternativa de esquerda à crise brasileira, organizado por Emir Sader (Rio de Janeiro, Relume-Dumará, 1993) que "O pluralismo (idéia proveniente do campo liberal) é, hoje, vital para uma política cultural vocacionalmente democratizadora"; p.168.

6 Herman Glasser, comunicação apresentada no Colóquio sobre Identidades, Políticas Culturales e Integración Regional, realizado em Montevidéu, de 21 a 23 de julho de 1993. In: Mundo, region y aldea (identidades, poltiticas culturales e integración regional), Hugo Achugar e Gerardo Caetano (eds.), Montevidéu, Trilce (no prelo).

7 Teixeira Coelho lança uma série de fatos relativos à circulação dos bens culturais e à ação cultural que poderiam trazer alguns elementos para a discussão de tais políticas culturais. Integraçāo, cultura e capacidade de regime ou para não ser alternativo no próprio país, na própria região. In: Mundo, region y aldea.

8 George Yúdice. Globalización y nuevas formas de intermediación cultural. In: Mundo, región y aldea.

Hugo Achugar é professor de Literatura Latino-Americana da Universidade da República de Montevidéu, Uruguai.

Palestra feita pelo autor no IEA-USP em 11 de novembro de 1993.

Tradução de Helena B. C. Pereira. O original em espanhol - La politica cultural en el Tratado del Mercosur - encontra-se à disposiçāo do leitor no IEA-USP para eventual consulta. 